\title{
EARLY FUNCTIONAL RESULTS OF BIOFEEDBACK AND ITS IMPACT ON QUALITY OF LIFE OF PATIENTS WITH ANAL INCONTINENCE
}

\author{
Fernando Rocha LEITE ${ }^{1}$, Marcílio José Rodrigues de LIMA ${ }^{1}$ and \\ Antônio LACERDA-FILHO²
}

\begin{abstract}
Context - Biofeedback has been used successfully in the treatment of fecal incontinence, working mainly on rehabilitation of the sphincter muscle. However, there are few studies presenting objective results of biofeedback, in terms of functional results and those related to the quality of life. Objectives - The aims of this study was to evaluate the immediate results of biofeedback in the treatment of fecal incontinence and its impact on the quality of life of patients by using validated questionnaires, correlating the results with those related to functional parameters of quality of life and clinical variables. Methods - We analyzed and compared the results of biofeedback in 52 patients with fecal incontinence before the start of the sessions and immediately after the end of them, by applying validated questionnaires assessing the degree of intensity of fecal incontinence (FISI - Fecal Incontinence Severity Index) and evaluation of quality of life related to fecal incontinence (FIQL - Faecal Incontinence Quality of Life Scale) as compared to clinical variables (age, onset of symptoms, etiology of the fecal incontinence, number of sessions of biofeedback and number and types of deliveries). Results - The evaluation of the results of FISI showed a significant increase in the number of individuals who had low severity scores of symptoms before and after the biofeedback (from 48.1 to $65.4 \%$ ) with $P=0.004$. There was significant improvements in domains of the FIQL, behavior $(P=0.008)$, depression $(P=0.006)$ and embarrassment $(P=0.008)$ after biofeedback. There was no significant correlation between the improvement of functional parameters evaluated by FISI and the improvement of quality of life. Positive correlation was found between the improvements of the domains of FIQL. There was no significant correlation between the results obtained using the FISI and FIQL with clinical variables assessed. Conclusions - Biofeedback has proven to be an effective therapy in the treatment of fecal incontinence, improving symptoms and/or quality of life for most patients, regardless of clinical presentation of this functional disorder.
\end{abstract}

HEADINGS - Biofeedback. Fecal incontinence. Quality of life. Questionnaires.

\section{INTRODUCTION}

Anal incontinence can be defined as the involuntary loss of gas or stool for a period greater than 1 month in an individual with at least 4 years of age ${ }^{(2,25)}$. It is a devastating condition for patients and their families, making it a difficult issue to be addressed by them and sometimes even by physicians, especially from the primary care( ${ }^{(8)}$.

Due to the progressive aging of the population, anal incontinence has become a real public health problem because it generates substantial morbidity and cost with clothes protectors (diapers, etc.), systemic and topical medications, nursing care, and spending not measurable related to impairment of quality of life and working capacity of patients.

Biofeedback is an important therapeutic tool used in treatment of this condition, based on the training of the pelvic floor muscles with the use of visual and/ or sound stimulus in order to obtain a more appropriate response in active exercises of contraction and relaxation ${ }^{(7)}$. This technique has been regarded as first-line treatment for patients with mild to moderate incontinence.

However, there are few studies in the literature reporting in an objective way, through the use of validated instruments, such as questionnaires and scales scores, functional results of biofeedback, as well as its 
impact on quality of life of patients with anal incontinence, either immediately after physiotherapy intervention or in long-term ${ }^{(25)}$. Thus, the aim of this study was to evaluate the early response of patients with anal incontinence underwent biofeedback therapy through the use of severity score of anal incontinence questionnaire and assessment of quality of life related to this condition, before and after treatment.

\section{METHODS}

We prospectively evaluated 52 patients with anal incontinence, characterized by involuntary leakage of gas or stool for a period greater than one month of any etiology in patients over 18 years old, underwent biofeedback treatment during the period from May 2009 to April 2011. We excluded those who were unable to understand the principles of biofeedback therapy or who had complete absence of contraction of anorectal sphincter or rectal sensitivity.

The etiology of incontinence was classified into three categories: traumatic (obstetrical or surgical injury or external violence), congenital (related to anorectal malformation) and idiopathic (neurogenic, degenerative, senile or nontraumatic causes).

After being informed of this study and agree to participate patients signed an informed consent and underwent a treatment program of 10 or 20 sessions of biofeedback, lasting 30 minutes, in the Instituto Mineiro de Gastroenterologia, conducted by the same physiotherapist (FRL).

The number of sessions, which essentially depends on the severity of incontinence and its initial response to treatment, was defined at the discretion of the physiotherapist. The patients with good response initially underwent 10 sessions and were observed. Those with poor or no response made over 10 additional sessions. Patients who showed no improvement after 20 sessions were considered as non-responders to the method and forwarded to the responsible physician for reassessment therapy.

Biofeedback sessions were held with electromyography instrument (Sandhill Scientific Inc., Littleton, Colorado, USA) connected to a microcomputer that generated the trace displayed by the patient and therapist simultaneously. The myoelectric activity was transmitted by electrodes attached to an endoanal plug (perry sensor) inserted into the rectum/ anal canal of the patient.

Patients initially adopted the supine position during the sessions. Then varied up postures (sitting, standing upright, etc), according to the evolution of each individual. The baseline of the electromyographic signals was obtained with the pelvic floor muscles at rest and closed in a range between 1 and $3 \mu \mathrm{V}$ (units of microvolts), which was on the $y$-axis of the graph reproduced by the computer. This path was altered by continued supervised exercise (contractions of the anal sphincter) objectively obtained by the patient.

The biofeedback sessions lasting on average 30 minutes and the patient was asked to repeat the series of contraction exercises at home from two to three times a day for 2 months or so.
The characterization of the severity of anal incontinence was assessed using the FISI questionnaire - Fecal Incontinence Severity Index. For its appliance, a frequency classification is presented to the patient, which should indicate that best describes each type of soiling. Summing the respective values scaled to each cell of this table and ranging from 0 to 61 determine the score. The results are directly related to the severity of symptoms, i.e., the higher the score, the more severe incontinence.

The FIQL questionnaire (Faecal Incontinence Quality of Life) was the specific instrument used to assess the quality of life of the research participants. This is a scale that comprises 29 questions divided into four areas, which represent groups of items related to quality of life: behavior, depression, embarrassment and lifestyle. Score scale ranging from 1 to 4 , with the exception of the issues 1 and 4, ranging from 1 to 5 and 1 to 6 , respectively. The score obtained by summing the items related to each domain, is inversely proportional to the impact of incontinence on quality of life of patients ${ }^{(28)}$.

Before the start of the first session of biofeedback and within the first month after the last session, functional outcomes and quality of life of each patient were assessed using the FISI and FIQL questionnaires, respectively. These questionnaires were delivered and completed in the clinic (IMEG), and in case of doubt about the filling, the researcher was asked directly.

An individual form containing the most relevant data identifying the patient's medical history (age, duration of symptoms, causes of incontinence, number of biofeedback sessions, number and types of delivery), as well as the etiology of incontinence was also completed before the start of the sessions of biofeedback.

The Committee on Ethics in Research at UFMG approved the present study. Data collection for research purposes only started after signing the informed consent form from the patient or guardian, according to Resolution 196/96 of the National Health Council.

\section{STATISTICAL ANALYSIS}

The data obtained by completing the FISI and FIQL questionnaires pre and post-treatment and medical forms were released in a standard questionnaire for the composition of the database of this study (Excel, Microsoft-2007) and submitted to statistical analysis.

Sample calculation performed prior to data collection demonstrated the need to recruit at least 33 patients to detect a medium effect with $80 \%$ statistical power. The sample characterization was performed by absolute and relative frequencies, mean and standard deviation. The data were analyzed in the statistical program SPSS version 13.0 (SPSS Inc. 2008, Chicago, Illinois, USA). The study variables that were part of FISI and FIQL were categorized by values less than or equal to and larger than the corresponding to the second quartile. The scattering data were grouped by median scores of all patients sample, as can be seen in Table 1 by exemplifying the cut-off points. 
TABLE 1. Cutoffs points of variables in FIQL and FISI scales

\begin{tabular}{lccccc}
\hline Variables & $\begin{array}{c}\text { FIQL } \\
\text { (Depression) }\end{array}$ & $\begin{array}{c}\text { FIQL } \\
\text { (Behavior) }\end{array}$ & $\begin{array}{c}\text { FIQL } \\
\text { (Embarrassment) }\end{array}$ & $\begin{array}{c}\text { FIQL } \\
\text { (Life style) }\end{array}$ & FISI \\
\hline Q2 & 25,00 & 27,00 & 9,00 & 30,00 & 34,00 \\
Cutoff & $<=25$ & $<=27$ & $<=9$ & $<=30$ & $<=34$ \\
& $>=26$ & $>=28$ & $>=10$ & $>=31$ & $>=35$ \\
\hline
\end{tabular}

$\mathrm{FIQL}=$ Faecal Incontinence Quality of Life Fecal; FISI=Incontinence Severity Index; Q2=second quartile

Three analyzes were performed, the first relating the results of FISI and FIQL scales before and after treatment with biofeedback through the Mac Nemar test. Then FIQL variables were compared with the result of FISI scale after treatment. Finally, the clinical variables of the study were correlated with the results obtained in FISI and FIQL after treatment. In these last two comparisons we used the Pearson chi-square test, exact and asymptotic. The significance level of $P<0.05$ was considered. We performed further Spearman correlation analysis to abnormal distribution of data between FIQL domains and the FISI scale and values of $P<0.05$ were considered significant.

\section{RESULTS}

Most of patients were female ( 50 or $96.2 \%$ ) with a mean age of $66 \pm 13$ years old, ranging from 30 to 90 . In $33(63 \%)$ patients, the cause of anal incontinence is traumatic, and the remainder (19 or 37\%) had idiopathic causes, mostly neurogenic type. No patient with congenital etiology was included in this study. The duration of symptoms was greater than one year in $36(71 \%)$ patients. There was a slight predominance of patients underwent 20 sessions of biofeedback $(52 \%)$. Of the 48 patients with obstetric history, $47.7 \%$ had between 1 and 3 deliveries and $34.1 \% 4-6$ deliveries. Six $(13.6 \%)$ women had seven or more children. Most patients ( 39 or $62.9 \%$ ) did not report trauma obstetric; forceps have been used in 18 of them (29\%). Two women were nulliparous.

Analyzing the incontinence severity scores (FISI) it was observed that, before treatment with biofeedback, 25 (48.1\%) individuals had a score less than or equal to 34. After therapy, this percentage increased to $65.4 \%$ (34 patients). The rate of incontinence with scores greater than 34 decreased from $27(51.9 \%)$ patients to $18(34.6 \%)$ individuals, pre and post intervention with biofeedback, respectively (Figure 1).

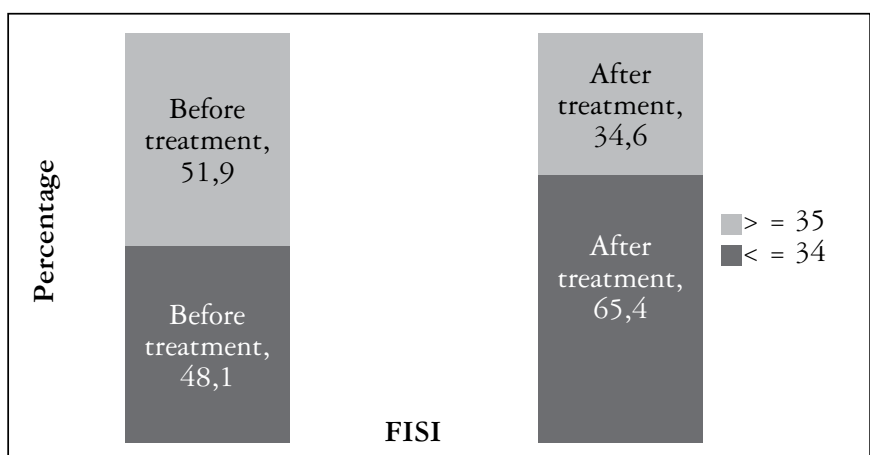

FIGURE 1. FISI before and after treatment - FISI improvement after biofeedback $(P=0,004)$
Regarding the FIQL, there was an increase in scores in the four domains (lifestyle, behavior, depression and embarrassment) after treatment with biofeedback. Figure 2 shows in relation to domain "lifestyle", the increase in score equal to or greater that 31 of $22(42.3 \%)$ individuals to $27(51.9 \%)$, respectively, in the pre and post treatment with biofeedback. We also observed a decrease in score less than or equal to $30,30(57,7 \%)$ for 25 patients $(48.1 \%)$, respectively, in the pre and post biofeedback, which is a trend towards improvement in lifestyle of patients participating in this study $(P=0.063)$.

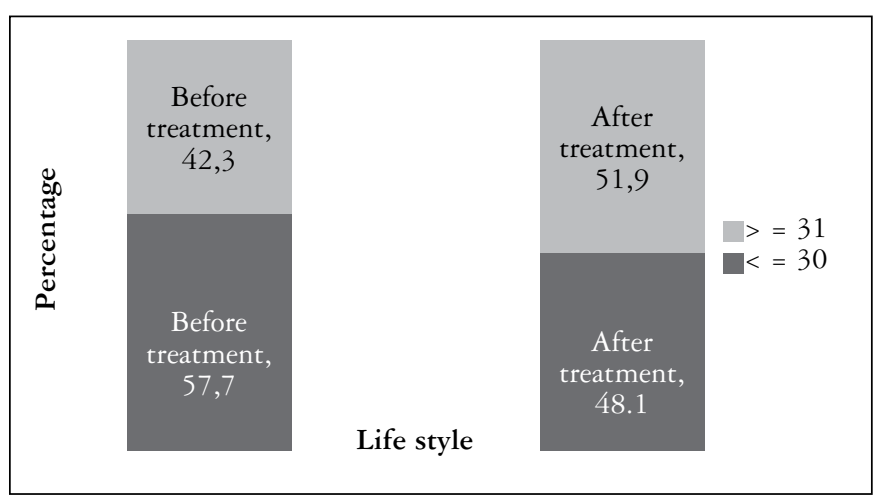

FIGURE 2. FIQL Domain of "lifestyle" before and after biofeedback shows trend towards improvement $(P=0.063)$

In the domain "behavior", patients with score less than or equal to 27 was $53.8 \%$ before treatment (28 patients). Following the treatment, this percentage dropped significantly to $38.5 \%$ (20 patients). As for those with scores greater than or equal to 28 , the rate increased significantly from $46.2 \%$ (24 patients) to $61.5 \%$ (32 patients) $(P=0.008)$ (Figure 3).

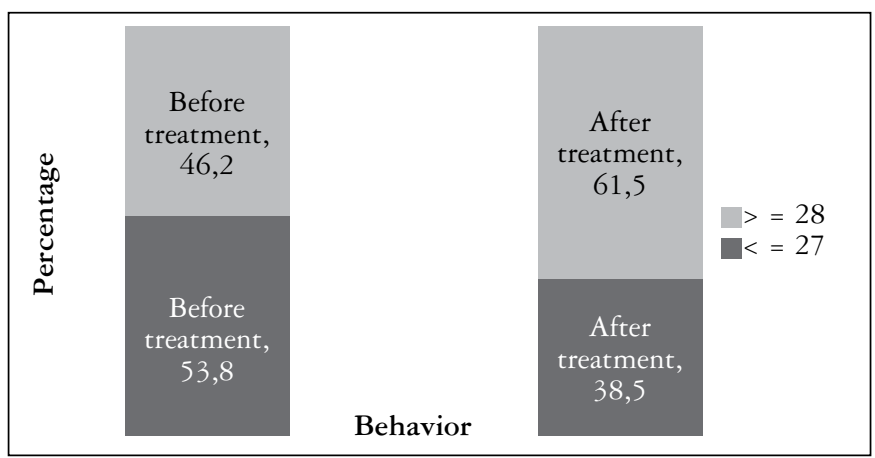

FIGURE 3. FIQL domain of "behavior" before and after biofeedback shows significant improvement $(P=0,008)$ 
Figure 4 shows that for domain "depression", a significant increase in the number of individuals with scores greater than or equal to $26,22(42.3 \%)$ individuals to $32(61.6 \%)$, pre and post biofeedback, respectively. Note also that there was a significant decrease in those with a score less than or equal to $25,30(57.7 \%)$ to $20(38.4 \%)$, with $P=0.006$.

With respect to domain "embarrassment", those with scores less than or equal to 9 corresponded to $26(50 \%)$ before treatment, reaching $18(34.6 \%)$ after the same. Furthermore, those with scores greater than or equal to 10 , the rate increased from 26 patients $(50 \%)$ to $34(65.4 \%)$ after treatment with biofeedaback $(P=0.008)$ (Figure 5).

There was no correlation between the scores obtained by FISI with the results of FIQL, using the Chi-square test, as shown in Table 2. Also by the Spearman test, no correlation was found between the scores of FISI and FIQL. As for the FIQL domains, positive correlation was demonstrated be-

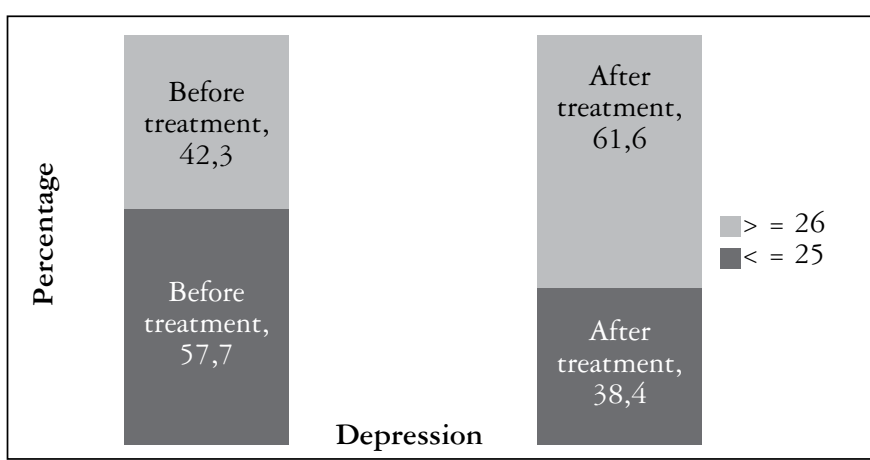

FIGURE 4. FIQL domain of "depression" before and after biofeedbac shows significant improvement $(P=0,006)$

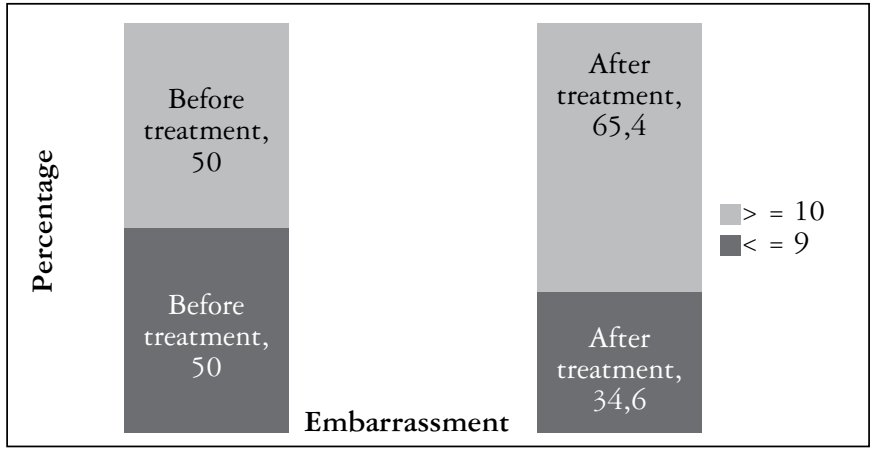

FIGURE 5. FIQL domain of "embarrassment" before and after biofeedback shows significant improvement $(P=0,008)$
TABLE 2. Results of association analysis between FISI and domains of FIQL after treatment with biofeedback

\begin{tabular}{|c|c|c|c|c|}
\hline \multirow{2}{*}{ Variables } & \multicolumn{3}{|c|}{ Post FISI } & \multirow{2}{*}{$\mathbf{P}^{*}$} \\
\hline & $<=34$ & $>=35$ & Total & \\
\hline $\begin{array}{l}\text { Post Life style } \\
\quad<=30 \\
>=31 \\
\text { Total }\end{array}$ & $\begin{array}{c}15(44,1) \\
19(55,9) \\
34\end{array}$ & $\begin{array}{c}10(55,5) \\
8(44,5) \\
18\end{array}$ & $\begin{array}{l}25 \\
27 \\
52\end{array}$ & 0,432 \\
\hline $\begin{array}{l}\text { Post Behavior } \\
\quad<=27 \\
>=28 \\
\text { Total }\end{array}$ & $\begin{array}{c}11(32,4) \\
23(67,6) \\
34\end{array}$ & $\begin{array}{c}9(50,0) \\
9(50,0) \\
18\end{array}$ & $\begin{array}{l}20 \\
32 \\
52\end{array}$ & 0,213 \\
\hline $\begin{array}{l}\text { Post Depression } \\
\quad<=25 \\
>=26 \\
\text { Total }\end{array}$ & $\begin{array}{c}13(38,2) \\
21(61,8) \\
34\end{array}$ & $\begin{array}{c}7(38,9) \\
11(61,1) \\
18\end{array}$ & $\begin{array}{l}20 \\
32 \\
52\end{array}$ & 0,963 \\
\hline $\begin{array}{l}\text { Post embarrassment } \\
\quad<=9 \\
>=10 \\
\text { Total }\end{array}$ & $\begin{array}{c}9(26,5) \\
25(73,5) \\
34\end{array}$ & $\begin{array}{c}9(50,0) \\
9(50,0) \\
18\end{array}$ & $\begin{array}{l}18 \\
34 \\
52\end{array}$ & 0,090 \\
\hline
\end{tabular}

*Pearsons Chi-squared asymptotic Test $(P<0.05)$

tween lifestyle and behavior, lifestyle and depression, embarrassment and lifestyle, behavior and depression, behavior and embarrassment and embarrassment and depression (Table 3).

Using the chi-square test, asymptotic and exact, it was observed that, for the clinical variables (age, duration of symptoms, causes of incontinence, number of biofeedback sessions, number and types of delivery) no correlations were observed with functional outcomes (FISI) or those related to quality of life (FIQL), in all domains, after the use of biofeedback.

\section{DISCUSSION}

The choice of the best treatment for anal incontinence is based fundamentally on the definition of etiology, assessment of the anatomical integrity of the anal sphincter complex and the effect of incontinence on quality of life of patients ${ }^{(26)}$.

The conservative treatment options for anal incontinence that include physiotherapy, especially biofeedback, have shown favorable results, according to several studies. They are painless and safe techniques, which aim to improve anal function (muscle strength, sensitivity, perception and coordination) and thus improve the quality of life and psychological wellbeing of patients ${ }^{(19,27)}$.

TABLE 3. Results of Spearman correlation test between FISI and FIQL scores

\begin{tabular}{|c|c|c|c|c|c|}
\hline Variables & FISI & Life style & Behavior & Depression & Embarrassmen \\
\hline FISI & & $-0,228(\mathrm{NS})$ & $-0,202$ (NS) & $-0,123(\mathrm{NS})$ & $-0,120(\mathrm{NS})$ \\
\hline Life style & & & $0,729 *$ & $0,539 *$ & $0,469 *$ \\
\hline Behavior & & & & $0,657 *$ & $0,630 *$ \\
\hline Depression & & & & & $0,675 *$ \\
\hline
\end{tabular}

*Strong positive correlations at the 0.05 level; $\mathrm{NS}=$ not significant 
However, many of the observations that biofeedback has beneficial effects in the treatment of anal incontinence are empirical, and the majority of published studies, does not show adequate methodology. It was demonstrated in a review based on a broad literature search that only five studies, from a total of 109 , were considered as scientifically relevant, and most of them had very small sample size, which compromised the extrapolations in the analyzes of results ${ }^{(20)}$. The variation of the methodology between the surveys also difficult to compare their results ${ }^{(29)}$.

In an extensive review on the use of biofeedback in anal incontinence, Rao mentions the different instrumentations and treatment protocols commonly used in this disorder, as well as the results obtained in 25 series analyzed ${ }^{(23)}$. Good results considered merely as "improvement" in incontinence were obtained in over $50 \%$ of patients, ranging from $54 \%$ to $92 \%$, with quite variable periods of follow-up. However, only three of these studies used validated questionnaires to measure the response reached ${ }^{(23)}$.

It is also known that the clinical manifestations presented by patients with anal incontinence may not correlate with the results of tests performed. That is, patients with very severe symptoms may present tests with few or mild changes, whereas some patients may experience mild symptoms with quite altered tests ${ }^{(17)}$. This highlights the lack of clinical correlation of incontinence symptoms with the results of objective tests, which may be associated with psychological factors, or even social, impacting quite differently, the quality of life of patients.

Considering the lack of reliable indicators of functional improvement of anal incontinence after therapeutic intervention, as well as the improvement of quality of life related to this dysfunction, we sought in this study, through a properly selected sample and the use of objectives scores, evaluate the impact of biofeedback in these patients.

Until now, the FISI, as well as other tools to measure the severity of anal incontinence, has not been translated, culturally adapted and validated for the Brazilian population ${ }^{(1)}$. However, as others, we chose to use this instrument in order to objectively assessing the severity of symptoms ${ }^{(1)}$ and possibly, their correlation with FIQL, questionnaire that assesses the impact of incontinence on QoL in patients undergoing biofeedback. FIQL has been validated for the Portuguese language and to Brazil in 2004 by YUSUF et al. ${ }^{(28)}$ and this is a specific scale to assess the quality of life of incontinent.

In relation to FISI, it was found that most individuals with incontinence improved immediate, substantial and objectively, after intervention with biofeedback. With the application of FIQL, we also demonstrated the positive impact of biofeedback in the quality of life of most patients, having been increased scores in all four domains (behavior, depression, embarrassment and lifestyle), and the first three observed statistically significant difference.

According to Boffi et al. ${ }^{(3)}$, using both questionnaires is crucial to determine the real impact of any therapeutic approach in improving symptoms related to anal incontinence. However, there is scarce number of studies based both on these two assessment tools ${ }^{(4)}$. When both were used, some authors have reported significant associations between the scores of the FIQL scale with the scores obtained in FISI ${ }^{(4,25)}$. This association, however, should be evaluated with caution, since patients with incontinence with the same level of severity can have their quality of life affected differently ${ }^{(24)}$.

In this study, there was no correlation of the parameters of FISI with the findings in the various domains of FIQL, through the application of two statistical tests (chi-square test and Spearman). Patients who improved FISI parameters were not necessarily those who had better response, in terms of quality of life, as measured by FIQL. Other authors also found no association between FIQL and severity index of anal incontinence - FISI ${ }^{(16)}$.

These results suggest that others factors besides the severity of the incontinence, may be associated with the maintenance or not of a good quality of life of these patients. Psychosocial issues are involved, as well as the resilience and coping capacity of each patient, which can be strongly implicated in the lack of correlation detected ${ }^{(1)}$.

It is noteworthy that, for the patient, a simple change in the frequency of incontinence episodes and the need for the use of protective clothing often means a significant change in their quality of life, even if the scales do not show an improvement in symptoms ${ }^{(2)}$. It might be noted that the improvement in QoL of patients also resulted in greater social conviviality and, consequently, less insulation, which causes feelings of greater self-esteem, although not observed an effective improvement in symptoms.

It is also believed that the therapist-patient relationship is critical to successful treatment. The information and instructions about treatment, clearly explained and adjusted to each patient understanding, foster the bond of trust in the professionals that accompany ${ }^{(18)}$. That was one of the reasons why it was decided, in this research, the participation of a single professional involved with the rehabilitation process.

Importantly, the mere hosting of such patients and demonstration of real interest in diagnosing and treating your condition can be considered essential step towards a better engagement in the therapeutic approach, and possibly strengthen their coping mechanisms.

There is however, must be kept in consideration that mechanical factors can influence the results, especially from a functional standpoint. Thus, a factor to be considered in these analyzes is the ability to start a minimal voluntary contraction of the external sphincter muscle as a prerequisite for the effectiveness of training with biofeedback. Probably, the worst results in the questionnaires may be related to those with major weakness of that muscle ${ }^{(11)}$.

The ability to understand the basics of training and the capacity of cooperation of the patient are also important criteria for treatment failure ${ }^{(15)}$. Patients unable to understand these principles have difficulty to interpret myoelectrical response provided by the device and displayed on the screen. Likewise, some patients are poorly able to exercise the muscles properly and coordinated when asked during the sessions, and especially in the home environment. This may be strongly 
related to the patient's capacity for discernment, which usually is related to the educational level of the individual, as well as their integration into the social context. This possible "social factor" was not evaluated in this study.

Although the sample size calculation indicates the need to recruit 33 patients to obtain statistical power of $80 \%, 52$ patients were included in this study, bringing this power to more than $90 \%$. The sample of individuals involved in this study was at its absolute majority, composed of elderly females. The literature confirms the predominance of female patients with anal incontinence, since they are more prone to obstetric trauma, in addition to hypoestrogenism and a higher prevalence of constipation with chronic straining, which can also cause or aggravate the stretching of the pelvic floor and pudendal innervation favoring the development of symptoms of incontinence ${ }^{(13,14)}$.

However, Christoforidis et al. ${ }^{(6)}$ comparing the data of 408 women and 85 men with anal incontinence, underwent a rehabilitation program, found after FISI assessment, that symptom severity between genders is quite similar. Despite the anatomical and physiological parameters between genders differ significantly, the impact of incontinence on quality of life is very similar in men and women ${ }^{(6)}$.

The effects of anal incontinence on the quality of life of the elderly, as well as the associated factors are not clearly defined in the literature. O'Keefe et al. ${ }^{(21)}$ observed that the presence of chronic diseases did not influence the effect of incontinence on QoL scores. This was also observed in the present study, where there was no association between age and the severity and/or impact of incontinence. Although the dysfunction is more common among elderly patients, it is worth noticing that younger patients with lower intensity of symptoms of incontinence tend to tolerate much less such symptoms due to increased interpersonal activity and productive working. These facts certainly impact more significantly the perception of QoL among these patients.

We did not confirm the association of age and gender with the severity and/or impact of incontinence on quality of life of patients. According to Jorge e Souza, these parameters do not really represent predictive factors in the outcome of biofeedback ${ }^{(12)}$.

With regard to obstetric history, generally associated with a higher risk of developing anal incontinence, Chiarelli et al found no such correlation, which also did not occur in this study. These authors also found no difference in rates of incontinence for primiparous women and/or multiparous, and multiparity was associated only with precursor symptoms, such as soiling and fecal urgency ${ }^{(5)}$.

Boffi et al. ${ }^{(3)}$ have shown the correlation between the severity of incontinence and its etiology. Patients with congenital or traumatic etiology presented generally more severe symptoms, requiring often, surgical treatment. But it is worth highlighting that in this study, no objective instruments were used to measure the improvement of patients undergoing biofeedback, making it difficult to assess the real benefit of this therapeutic intervention in patients with anal incontinence ${ }^{(3)}$. In the present study there was no association of the etiology, traumatic or idiopathic, with response to biofeedback.

Dobben et al. ${ }^{(10)}$ studied 266 patients (91\% female) and using another scale of symptom severity score (Vaizey) observed that the improvement in incontinence with the use of biofeedback was not associated with age, duration of symptoms, menopause or even results in tests, including anorectal manometry. Such clinical observations coincide with those observed in the present study.

The sample size calculation was concerned only with the initial and final scores of response to treatment with biofeedback. So it was not done statistical work for the association analyzes of each variable (uni or multivariate). With a larger sample size, power would perhaps notice a few of these correlations.

There is no consensus regarding the optimal amount of sessions and duration of treatment of pelvic floor rehabilitation. The present study confirms that weekly biofeedback sessions, lasting approximately 30 minutes each, are an effective resource for the treatment of anal incontinence, regardless of the number of sessions. Through objective analysis were achieved results that showed improvement in symptoms and its positive impact on quality of life, after the application of biofeedback.

Therefore, biofeedback should always be considered as an important therapeutic option for patients with anal incontinence, regardless of patient age, etiology and progression of the disorder. Although not completely effective in improving symptoms, this therapeutic approach is able to support and give confidence to the patient, allowing greater ability to cope with their condition and consequently improves their quality of life, soon after the treatment. As a perspective, must be evaluated in the long term, if these results sustain themselves, what has already been demonstrated by other authors, however, without the use of specific instruments to measure ${ }^{(9,15)}$.

Leite FR, Lima MJR, Lacerda-Filho A. Resultados funcionais imediatos do biofeedback e seu impacto na qualidade de vida de pacientes com incontinência anal. Arq Gastroenterol. 2013,50(3):163-9.

RESUMO - Contexto - O biofeedback vem sendo utilizado com sucesso no tratamento da incontinência anal, atuando, sobretudo, na reeducação da musculatura esfincteriana. Existem, entretanto, poucos estudos que apresentam resultados objetivos, do ponto de vista funcional e relacionado à qualidade de vida, da aplicação do biofeedback em portadores de incontinência anal. Objetivos - Avaliar os resultados imediatos do biofeedback no tratamento da incontinência anal e seu impacto na qualidade de vida dos pacientes por meio da utilização de questionários validados, correlacionando os resultados funcionais com aqueles relacionados aos parâmetros de qualidade de vida e com variáveis clínicas. Métodos - Foram analisados e comparados os resultados do biofeedback em 52 pacientes com incontinência anal, antes do início das sessões e logo após o término das mesmas, por 
meio da aplicação de questionários validados de avaliação do grau de intensidade da incontinência fecal (FISI - Fecal Incontinence Severity Index) e de avaliação da qualidade de vida relacionada à incontinência fecal (FIQL - Faecal Incontinence Quality of Life Scale), assim como em relação às variáveis clínicas (idade, tempo de evolução dos sintomas, causa da, número de sessões de biofeedback e número e tipos de partos). Resultados A avaliação dos resultados da aplicação do FISI demonstrou aumento significativo do número de indivíduos que apresentavam baixos escores de gravidade de sintomas antes e após a realização do biofeedback (de 48,1\% para 65,4\%) com $P=0,004$. Houve significativa melhora dos domínios do FIQL, comportamento $(P=0,008)$, depressão $(P=0,006)$ e constrangimento $(P=0,008)$ após a aplicação do biofeedback. Não se observou correlação entre a melhora dos parâmetros funcionais avaliados pelo FISI com a melhora da qualidade de vida. Foi observada correlação positiva entre a melhora dos domínios do FIQL. Não se observou correlação entre os resultados obtidos pela aplicação do FISI e do FIQL com as diversas variáveis clínicas avaliadas. Conclusões - O biofeedback pode ser considerado como uma terapêutica eficaz no tratamento da incontinência anal, melhorando a sintomatologia e/ou a qualidade de vida da maioria dos pacientes, independente da apresentação clínica desse distúrbio funcional.

DESCRITORES - Biofeedback. Incontinência fecal. Qualidade de vida. Questionários.

\section{REFERENCES}

1. Barbosa JMM. Avaliação da qualidade de vida e das estratégias de enfrentamento em idosos com incontinência fecal. [Dissertação de Mestrado]. Belo Horizonte: Escola de Educação Física, Fisioterapia e Terapia Educacional - UFMG; 2006.

2. Bharucha AE, Wald A, Enck P, Rao S. Functional anorectal disorders. Gastroenterology. 2006;130:1510-8.

3. Boffi A, Ayabaca S, Corradi A, Renzi C, Pescatori M. Etiology and severity of symptons of fecal incontinence: is there a correlation? Int J Colorectal Dis. 2002; 17:59-60.

4. Bordeianou L, Rockwood T, Baxter N, Lowry A, Mellgren A, Parker S. Does incontinence severity correlate with quality of life? Prospective analysis of 502 consecutive patients. Colorectal Dis. 2008;10:273-9.

5. Chiarelli P, Murphy B, Cockburn J. Fecal Incontinence after high-risk delivery. Obstet Gynecol. 2003;102:1299-305.

6. Christoforidis D, Bordeianou L, Rockwood TH, Lowry AC, Parker S, Mellgren AF. Faecal incontinence in men. Colorectal Dis. 2011;13:906-13.

7. Cook TA, Mortensen NJ. Management of faecal incontinence following obstetric injury. Br J Surg. 1998;85:293-9.

8. Cooper ZR, Rose S. Fecal incontinence: a clinical approach. Mt Sinai J Med. 2000;67:96-105.

9. Davis KJ, Kumar D, Poloniecki J. Adjuvant biofeedback following anal sphincter repair: a randomized study. Aliment Pharmacol Ther. 2004;20:539-49.

10. Dobben AC, Terra MP, Berghmans B, Deutekom M, Boeckxstaens GE, Janssen LW, Bossuyt PM, Stoker J. Functional changes after physiotherapy in fecal incontinence. Int J Colorectal Dis. 2006;21:515-21.

11. Fynes MM, Marshall K, Cassidy M, Behan M, Walsh D, O'Connell PR, O'Herlihy C. A prospective, randomized study comparing the effect of augmented biofeedback with sensory biofeedback alone on fecal incontinence after obstetric trauma. Dis Colon Rectum. 1999;42:753-8.

12. Jorge JMN, Souza MM. Biofeedback. In Paula-Castro L, Coelho LGV. Gastroenterologia; Rio de Janeiro: 2004. p. 1451-4.

13. Jorge JM, Wexner SD. Etiology and Management of Fecal Incontinence. Dis. Colon Rectum. 1993;36:77-97.

14. Lacerda-Filho A, Lima MJ, Magalhães MF, Paiva Rde A, Cunha-Melo JR. Chronic constipation - the role of clinical assessment and colorectal physiologic tests to obtain an etiologic diagnosis. Arq Gastroenterol. 2008;45:50-7.

15. Laudanno OM, Lantorno G, Tomé M. Biofeedback: metodo simple y eficaz en el tratamiento de la incontinencia fecal. Acta Gastroenterol Latinoam. 1996;26:105-10.
16. Lehur PA, Zerbib F, Neunlist M, Glemain P, Bruley des Varannes S. Comparasion of quality of life and anorectal function after artificial sphincter implantation. Dis Colon Rectum. 2002;45:508-13.

17. Liberman H, Faria J, Ternent CA, Blatchford GJ, Christensen MA, Thorson AG A prospective evaluation of the value of anorectal physiology in the management of fecal incontinence. Dis Colon Rectum. 2001;44:1567-74.

18. Miner PB, Read NW. Investigation of mode of action of biofeedback treatment of fecal incontinence. Dig Dis Sci. 1990;35:1291-8.

19. Norton C. Behavioral management of fecal incontinence in adults. Gastroenterol. 2004;126:64-70.

20. Norton C, Hosker G, Brazelli M. Biofeedback and/or sphincter exercises for the treatment of faecal incontinence in adults. Cochrane Database Syst Rev. 2006;19:CD002111.

21. O'Keefe EA, Talley NJ, Zinsmeister AR, Jacobsen SJ. Bowel diseorders impair functional status and quality of life in elderly: a population based study. J Gerontol A Biol Sci Med Sci. 1995;50:M184-9.

22. Oliveira, L. Incontinência fecal. [Internet]. J. Bras Gastroenterol. 2006;6:35-7. Available from: http://socgastro.org.br/site/scripts/revistas/jbg01/jbg106incfecal.pdf.

23. Rao SS; American College of Gastroenterology Practice Parameters Committee. Diagnosis and Management of fecal incontinence. Am J Gastroenterol. 2004;99:1585-604.

24. Rockwood TH, Church JM, Fleshman JW, Kane RL, Mavrantonis C, Thorson AG, Wexner SD, Bliss D, Lowry AC. Patient and surgeon ranking of the severity of symptoms associated with fecal incontinence: the fecal incontinence severity index. Dis Colon Rectum. 1999;42:1525-32.

25. Rockwood TH. Incontinence severity and QOL scales for fecal incontinence Gastroenterology. 2004;126:S106-13.

26. Soffer EE, Hull T. Fecal incontinence: a practical approach to evaluation and treatment. Am J Gastroenterol. 2000;95:1873-80.

27. Whitehead WE, Wald A, Norton NJ. Treatment options for fecal incontinence. Dis Colon Rectum. 2001;44:131-42.

28. Yusuf SA, Jorge JM, Habr-Gama A, Kiss DR, Rodrigues J. [Evaluation of quality of life in anal incontinence: validation of the questionnaire FIQL (Fecal Incontinence Quality of Life)]. Arq Gastroenterol. 2004;41:202-8.

29. Zutshi M, Salcedo L, Hammel J, Hull T. Anal physiology testing in fecal incontinence: is it of any value? Int J Colorectal Dis. 2010;25:277-82.

Received 4/1/2013 Accepted 7/5/2013. 